\title{
Utilization of knowledge management and information technologies theory in water resources management
}

\author{
M. Toman \\ Department of Hydrotechnics, Faculty of Civil Engineering, \\ Czech Technical University in Prague, Czech Republic
}

\begin{abstract}
Project AQUINpro, described in this paper, derives from a common theory of knowledge management and information technologies. The aim it to expand the theory to the water resources management field in the Czech Republic, a theory that is not currently being applied. Methods of knowledge management allow for much more space for thinking about the substance of water management problems beyond that of the application of partial artificial intelligence methods. The way of solving of water management problems will be possible by finding an effective, elegant and especially simpler way with the use of knowledge and expert systems. Knowledge and expert systems are very effective tools for working and exploiting important knowledge about the operations and control of complicated systems. Such systems are water management systems, which have specific dynamic properties and their real-time control proceeds often in conditions of uncertainty. Expert systems are above all much preferable for operation than conventional algorithms because they are able to imitate logical thinking of the human factor. For solving problems in water management it is necessary to use, what has been until now, a nonexistent methodology. Systems of knowledge management can be suitably adapted to be helpful for extreme situations and for training purposes. It is not always possible for operatives to be involved in solving problems of extreme flood situations in real time, which did happen in the recent past in the Czech Republic. Recent experience of managing flood situations in the year 2002 has highlighted the necessity to methodically develop the generally applicable, fundamental, operational and decision making rules behind extreme situations. It is necessary to do this as soon as possible, in order not to loose recently gained valuable knowledge and experience. Knowledge technologies have now been employed in a number of different areas and the results of these projects can be used as a theoretical background for implementing of knowledge management tools to the water management companies.
\end{abstract}

Keywords: water management, knowledge and information technologies, optimization of control. 


\section{Summary of contemporary knowledge state about the given problem}

Utilization of artificial intelligent methods or use of intelligent systems, especially expert systems in complex elements and processes control is, in spite of some known risks or failures, very progressive, and such systems are broadly utilized in a number of areas. In other parts of the world, these problems are solved by organisations such as the IIASA institute in Vienna, and in NATO by specialized workplaces within the headquarters in Brussels that are also interested in this field. Applications of expert systems for the control of complex facilities, like water treatment plants and wastewater plants are designed and utilized in water management throughout the world. Expert systems that evaluate ecological impacts of different constructions are another type of their exploitation. As far as other fields are concerned the largest exploitation of expert systems has been in medicine (diagnostic systems), in the control of complex technological industry processes, in the energy industry, in space research (for example within the bounds of NASA) and in military applications. At the International Conferences on the Application of Artificial Intelligence (AI) in engineering disciplines - AIENG (in July 1995, in Udine, Italy; in July 1996, in Florida, USA; in July 1997, in Capri, Italy; in July 1998, in Galway, Ireland), International Water Association Conference "Management of Productivity at Water Utilities" (June 2002, Prague, Czech Republic) or at conferences River Basin Management and Water Resources Management (for example April 2003, Las Palmas, Gran Canaria) it was demonstrated on some applications, that expert system applications for the area of water management seem to be very promising.

In countries with advanced technologies, any utilization of artificial intelligence methods in water management is considered to be strategically important. Applications of computers and robotics are broadly supported as well as the development of software for operators' decision support in complex system environments, which require large amount of information, experience and knowledge to be controlled, i.e., require knowledge and expert systems development. In our situation the adoption of these progressive methods is slow, however, a good understanding of the potential benefits for their applications exist and in some cases are being utilized, as in the River-basin enterprises where a routine has already started of automated information systems for the collection and transfer of data from river-basins to the control centres.

The first application of a classic expert system approach in water resources management was solved in the scope of the grant of the Faculty of Civil Engineering of Czech Technical University in Prague (No. 1032 and No. 2027) in 1995 and 1996. The applicable prototype of an expert system was developed in the professional development software NEXPERT Object of the Neuron Data Company. The developed knowledge-based system has been controlling the system of three reservoirs by the water resources management control based on the adaptive principle in dry periods. It had been tested using hydrologic data of the reservoirs Kružberk, Šance a Morávka, supplying the drinking water to the 
Ostrava region. The second water resources management application seems to be a prototype of knowledge-based system aimed at optimal manipulations design for water reservoirs of the cascade Slezská Harta, Kružberk and Podhradí so that the maximum electrical energy production can be achieved on the cascade's small electrical power plants, based on Ostrava's region decreased demand for the drinking water supply.

Recently, the project of the Grant Agency of the Czech Republic, No. 103/01/0036 "AQUIN - Utilization of Information Technologies for Optimization Control in Water Management" has been, in the last few years, a direct continuation of the previously mentioned research initiatives. The goal of the project has been to utilize expert systems and knowledge management methods into still very rare water management applications, to achieve important results and contribute thus to their popularization throughout the professional community and consequently also to their broader practical utilization. This goal has been achieved successfully by the development of a prototype knowledgebased system for the reservoir Nýrsko, controlled by the dispatch centre of the River-basin Vltava state enterprise - branch plant Berounka.

Controlling of any process, including controlling of water management, requires knowledge, if it is supposed to be effectively applied in everyday practice. This knowledge is often only available to a small group of specialists (experts), who know when, how and what should be done to ensure a failure-free and sufficient water supply to households, or industry, or to properly manage dramatic flood threads. This knowledge may not always be available for several reasons - experts may not be always available when they are needed, their knowledge and expertise may be lost when they move away or change jobs or they may differ in opinion on how to best solve a specific problem and this may lead to disturbances and delays in solving the problem.

Knowledge can also be hiding in data. Tools for so called machine learning and data mining based on statistic methods are possible to use for getting such data.

For this reason such a solution is appropriate in the domain of water management control that is based on principles of knowledge management using suitable knowledge tools which have proven their usability in other areas.

The area of knowledge management, which is intended to be applied largely in the proposed project, utilizes systematic approaches to identification, understanding, and application of knowledge in order to create new values. It is also a formalization of various approaches based on areas such as artificial intelligence, knowledge based systems, organizational management, etc., aiming to such a treatment of experience, knowledge, or expertise of human specialists, which will lead to the building of new possibilities supporting an increase in intellectual power, introduction of innovations, and enhancing services for future users. Recently, a number of various organizations have already started to introduce at least some parts of the big palette of principles, methods, and tools of knowledge management as well as of the ontological engineering, aimed at sophisticated creation of an explicit specification of important concepts of the problem domain. That is the reason why this application area of research 
deserves increased attention in water management. The ultimate goal of introducing knowledge management in a company is to collect all the important knowledge (explicit or so-called tacit, that can be found mainly in experts heads) and make it available - shared through the entire company. Usually this task is accomplished using well developed knowledge technologies such as knowledgebased or expert systems.

\section{The aim formulation, the schedule of the project and expected outputs, project applicants and their institutions}

The goal of the project AQUINpro is an investigation of knowledge transfer, reusing and sharing possibilities in the domain of water management. The research will focus on design of knowledge models specific to control structures of water management and suggestions of appropriate models. Based on the project AQUIN experience and by enriching expert knowledge so far acquired with knowledge specific to other water systems of the River-basin Vltava state enterprise - branch plant Berounka, knowledge models will be created by using methodology of ontology engineering. These models will be used directly for developing several knowledge-based DSS for each of the water systems mentioned earlier, and it will be enable sharing and transferring knowledge contained in these systems, independently on used implementation tool. It will give a base for introducing knowledge management approaches and tools in the River-basin Vltava state enterprise - branch plant Berounka, later on.

Development of knowledge-based system application prototypes will be accomplished by using "Jess" environment for expert systems development. It is a free development environment, which is a successor of the older system CLIPS. The system CLIPS has been used in the previous project AQUIN. In Jess environment it is possible to create applications by declarative ways, i.e. to formulate knowledge in the facts and rules form. The implemented inference mechanism then manipulates with rules, it is possible to work with fuzzy logic and with object oriented programming components. In Jess system it is possible to equip the created application with a useful user interface, unlike the CLIPS system.

The project was carried out over a period of three years. In the last year (2006) the procession of basic material and data supplied by the River-basin Vltava state enterprise came through with an enrichment of acquired expert knowledge specific to further water schemes. Working from this data the selection of knowledge technologies for the next data processing (case-based reasoning, data mining, pattern matching) was accomplished and adequate software was selected.

In this year (2007) the water reservoirs problem domain knowledge models are being developed using ontological engineering principles and three corroborative decision support systems:

1. Algorithmization of the technological procedures from water structures manipulation rules. 
2. System for identification, evaluation and sampling of previous decision scenarios from which is possible to choose the decision in this exact moment.

3. Knowledge simulation of river basin saturation trend that exploits rainfallrunoff river basin model for testing of decision support scenarios.

In the year 2008 - testing, tuning a practical verifying of the knowledge management application, evaluation of achieved results, their presentation and an eventual proposal of further application of the project results will be carried out.

In the frame of the project prototypes of knowledge-based decision support systems for optimization of water structures control in partial basins of the River-basin Vltava state enterprise - branch plant Berounka (principally of those of Mže (for example see fig. 1), eventually Střela or Radbuza) will be developed on the basis of created knowledge models. These prototypes will be tested, debugged and verified in practice.

Anticipated scientific outputs of the project will be beneficial in the domain of water resources management and in the area of applied information and knowledge technologies, and they will contribute to knowledge and experience of these fields. The outputs will encourage further research efforts and will enrich university education. They will become a definite scientific contribution and they will significantly enhance the usage of information technologies in the area of water management.

The project solver - Doc. Ing. Michal Toman, PhD. - has been working eighteen years in the field of water resource systems, applied hydrology and hydraulic at the Department of hydrotechnics, Faculty of Civil Engineering, Czech Technical University (CTU) in Prague. Recently, he was the responsible solver of the grant project (Grant Agency of Czech Republic, No. 103/01/0036) "AQUIN - Utilization of information technologies for optimization control in water management". He participates in the research in above-mentioned scientific disciplines and he solved the development of expert system for complex water resource system in the range of internal grants of Faculty of Civil Engineering of CTU (No. 1032 and 2027 in 1995 and 1996). He has experience from the research of artificial intelligence methods in the theory of water resource systems (Grant Agency of Czech Republic, No. 103/97/0106) and he is author or co-author of software equipment for relevant research tasks. He published research results as co-author with his colleagues and he presented these results at international specialized conferences (10th and 12th International Conferences on the Application of AI in engineering disciplines, in July 1995, in Udine, Italy and in July 1997, in Capri, Italy; International Water Association Conference "Management of Productivity at Water Utilities", June 2002, Prague, Czech Republic; "River Basin Management 2003" and "Water Resources Management 2003”, April 2003, Las Palmas, Gran Canaria).

The first project joint solver - Prof. Ing. Peter Mikulecký, PhD. - is a recognized specialist in the field of the information and knowledge technologies applications (especially knowledge-based systems) and in the area of knowledge management. Professor Mikulecký is the head of the Department of Information Technologies, Faculty of Informatics and Management of the University of Hradec Králové, where he is also the Director for research, with a responsibility 
for the doctoral degree programme. He supervises 8 doctoral students in the programme Information and Knowledge Management. His scientific interests include decision support systems, knowledge and expert systems, knowledge management and human-computer interaction. $\mathrm{He}$ is foreign member of accreditation committee of the Slovak Republic government, a member of a number of Czech and international professional organizations; he has participated in many research projects (e.g. 5th Framework Programme, Socrates, Tempus, Leonardo da Vinci, etc.). He led a project of Grant Agency of Czech Republic (No. 201/99/0950, 406/04/2140), a project of INFRA programme no. LB98217 and recently is the principal researcher of a research project of the Ministry of Education MSM 184500001 "Knowledge Management for Information Society".

The second project joint solver - Ing. Jan Janda - represents the practice. He is the director of the River-basin Vltava state enterprise - branch plant Berounka in Plzeň. He is very open to ideas of introducing new ways of control into practice. He is interested in hydrology, in hydro technical constructions and in operations on rivers. He also preserves very productive contacts with research basis and his enthusiasm to be active in problem solving within his company guarantees immediate verification and consequential utilization of research results in practice.

The project solver, joint solvers and their co-workers constitute the team of specialists with considerable knowledge and experience in the given research area. Therefore the project is in safe hands from the professional and scientific point of view. Immediate practical connections are supported.

\section{Conception and methodical approaches for the solution of the project and their analysis}

Given current problems of water resources management, a research should be promoted, suitable methodical procedures should be sought and new scientific disciplines should be developed that join together for example hydraulics and hydrology with modern knowledge and information technologies in order to simulate the operation of water management structures in various situations and different environmental conditions and influences.

Keeping in mind the objectives of the project, we should identify the difference between important, moderately important and unnecessary types of knowledge. Important types of knowledge will gradually gain importance as the work on the project proceeds and the objectives of the project will be eventually broadened. The moderately important types of knowledge may also become important in the case of modification of the project's goals.

Knowledge sources may differ in the profundity of knowledge they offer. Some knowledge sources have a form of a professional textbook which serves theoretical background knowledge of the domain. Water scheme operating instructions are another source based on an analysis of historical data characterizing climate, river basin and the reservoir behaviour. Heuristic knowledge of dispatchers is usually considered as the most valuable type 
knowledge. Dispatchers gained deep operation knowledge about the behaviour of the entire river basin and water management structures along the river. The source of this type knowledge is naturally the personal of the river basin management company's decision making centre.

One of the most important criteria of the identification of potentially suitable knowledge source is its availability. Here expectations generally do not correspond to the reality and many potentially interesting knowledge sources may later on turn out as inaccessible or unrecoverable.

An important factor is also the reliability of the knowledge sources used. Many of them consist of a complete series of correctly measured data but it can not be ruled out them some part of the data is missing or got damaged during a transfer from one data medium to another. A big part of available knowledge may be uncertain or inexact. This may be the case of dispatchers' heuristic knowledge but, on the other hand, the heuristic knowledge is the most valuable knowledge that constitutes the base of the knowledge-based DSS in development. For this reason a task of extracting and representing heuristic knowledge is one of the most difficult and most important tasks. Suitable methods for resolving the mentioned tasks can be found in some of the listed references.

\section{Expected results of the project AQUINpro and their utilization}

Knowledge-based systems and their application in water resources management are successfully accepted in the every day practice of water management owing to focused research in the frame of AQUIN project. The proposed project is a continuation of the original research work in this area and its outputs will be of concrete benefit for every day practice. Current experiences of the River-basin Vltava state enterprise - branch plant Berounka (the second joint applicant) show that solutions reached are useful and important for the control of water management and for the updating of manipulation and operating instructions of water schemes.

Based on experience gained from previous projects the goal of the current project is to develop knowledge-based applications in the domain of water management. Using knowledge technologies the solution of a practical problem can be enhanced and widened. Using the above mentioned knowledge technologies the solution of practical problems of the River basin management company Vltava, branch Berounka, as well as potential flood risks or the solution of non-supply of water in extreme dry periods can be achieved and enhanced. In the frame of the proposed project the achieved experience will be applied also at other river sheds of Berounka (particularly river basin Mže with water schemes Hracholusky - see fig. 1 and Lučina, optionally river basin Střela with water scheme Žlutice or river basin Radbuza with water scheme České údolí). 


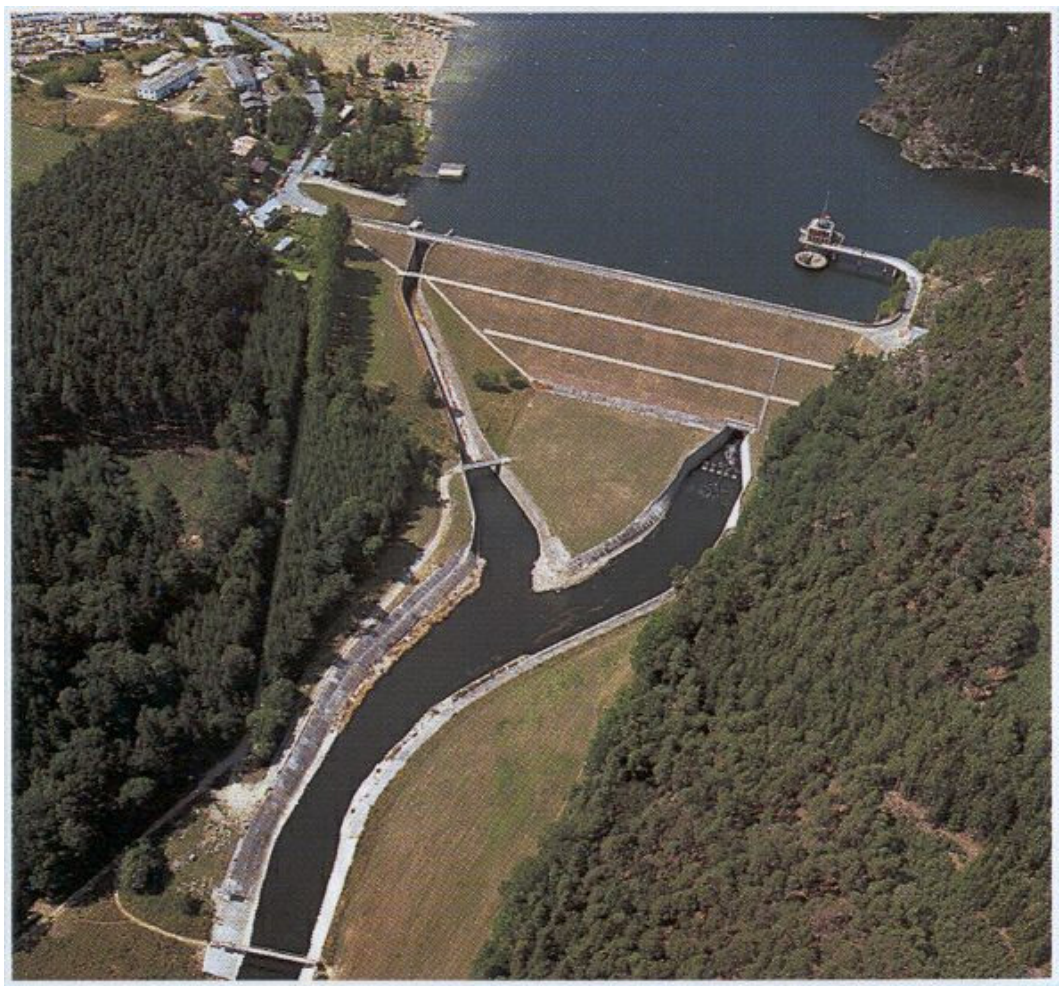

Figure 1: Hracholusky Dam.

\section{The significance of the project for water management practice}

In the domain of water resources management a whole range of up-to-date problems exist that require a solution. First of all, models of optimal utilizing of water in reservoirs, rainfall-runoff forecasting models, models of river pollution propagation, models of water quality control in reservoirs etc. can be listed and currently flood and flood situations forecasting models can also be mentioned.

Knowledge-based systems to be developed and can be then used in decision making centres of the river basin companies in order to improve the quality of real-time control and decision making where special attention will be paid to specific local geomorphologic and hydrological circumstances. The significance of knowledge-based systems utilizing lies especially in the possible training of new incoming dispatchers for conditions of control and in practice the decision making processes of current staff of decision making centres. The systems may 
be also used in a formulation of new approaches to protection against floods at a national and international level.

Contemporary rapid expansion of technologies and production procedures came to be more complicated, as was the processes of their control. It presents a stressful problem for man and may become, that the ability to control such processes can fail. It could lead to considerable economical and ecological collapses. A reasonable way for prevention of such complications is increasing safety factor of human control activity by use of decision supporting systems from the artificial intelligence area. It means that we have to focus on the development of knowledge and expert systems and on their propagation.

Management of water resources is task that is impossible to solve independently on all existing inner and outer structures and surroundings. The resolution of their optimal exploitation is therefore using new system and methodical techniques. At the present time the research into optimal operative management of water sources and water management elements is undertaken by the individual water management dispatching centres of river-basin companies. It is a wide research area with many important practical problems, e.g. operation optimalization of check gate, efficient power usage of small hydraulic power plants, automatization of navigation elements, flows and flood forecasting and solving of their possible consequences, real - time control of complicated water management systems of reservoirs and waterways, monitoring and water quality management in reservoirs, operating of drawing mechanisms of waterways, outlets and protective spillways constructions, water transport management etc.

For all of these problems it is possible to effectively use progressive technology of knowledge and expert systems. Large perspectives of their usage is especially in an analysis of water management construction ecological impacts, they may help to estimate a progression of flood situations and design for an appropriate manner of operative intervention and as well to optimise decision-making processes in water management dispatching centres.

\section{Acknowledgements}

This paper was supported by Czech Science Foundation project no. 103/06/1247 AQUINpro - Intelligent Decision Support Systems for Water Management Dispatch Centres.

\section{References}

[1] Toman, M., Mikulecký, P., Olševičová, K. \& Ponce, D.: Knowledge Technologies in Water Management. CTU Publishing Company, Prague, 2004, 205 pp., ISBN 80-01-03049-0.

[2] Olševičová, K. \& Ponce, D.: Knowledge analysis of the system for water reservoir control. International Conference on Hydrology: Science \& Practice for the 21st century, 12-16 July 2004, London. 
[3] Mikulecký, P.: On the Way to Knowledge-Based Water Management. In: The BHS 2004 Intl. Conf. on Hydrology: Science and Practice for the 21st Century. 12-16 July 2004, London.

[4] Toman, J. \& Toman, M.: Water Balance of the Reservoir Nýrsko. Design Material for Operating Regulations Actualization. Prague, March 2004, 53 pp.

[5] Mikulecký, P.: A Knowledge Management Application in Decision Making. In: Proc. of the 2nd Int. Conference m-ICTE 2003, Badajoz, 3.6.12.2003, pp. 308-311, ISBN 84-96212-10-6.

[6] Toman, M. et al.: Project AQUIN - Annual Report for a Year 2003, CTU in Prague, Faculty of Civil Engineering, November 2003, Research report of the project GAČR - no. 103/01/0036, 117 pp.

[7] Mikulecký, P., Ponce, D. \& Toman, M.: A knowledge-based solution for river water resources management. In: Water Resources Management II. Southampton, WIT PRESS 2003, pp. 451-458, ISBN 1-85312-967-4.

[8] Mikulecký, P., Ponce, D. \& Toman, M.: A knowledge-based decision support system for river basin management. In: River Basin Management II. Southampton, WIT PRESS 2003, pp. 177-185, ISBN 1-85312-966-6.

[9] Toman, M. et al.: Project AQUIN - Annual Report for a Year 2002, CTU in Prague, Faculty of Civil Engineering, January 2003, Research report of the project GAČR - no. 103/01/0036, 82 pp.

[10] Hynek, J. \& Slabý, A.: Why Evolutionary Algorithms Fail? The Contribution at International Conference Learning '02. Universidad Carlos III de Madrid, October 23 - 25, 2002, Madrid, Spain, pp. 47 - 52.

[11] Ponce, D., Mikulecký, P. \& Toman, M.: Application of Qualitative Reasoning in Hydropower Plant Control. In: International Water Association Conference "Management of Productivity at Water Utilities", 12.6. - 14.6.2002, Prague, p. 191.

[12] Mikulecký, P., Ponce, D. \& Toman, M.: Possibilities for Knowledge Management Solutions in Water Management. In: International Water Association Conference "Management of Productivity at Water Utilities", 12.6. - 14.6.2002, Prague, p. 96.

[13] Toman, M., Mikulecký, P. \& Ponce, D.: Knowledge-based and Expert Systems Utilization to Improve the Control and Optimization Processes in Water Management Dispatch Centers in Real Time. In: International Water Association Conference "Management of Productivity at Water Utilities", 12.6. - 14.6.2002, Prague, pp. 107 - 112.

[14] Toman, M. et al.: Project AQUIN - Annual Report for a Year 2001, CTU in Prague, Faculty of Civil Engineering, January 2002, Research report of the project GAČR - no. 103/01/0036, 63 pp.

[15] Toman, M. \& Mikulecký, P.: Expert Systems and Its Perspective in Water Resources Management. Water Management, 50, 2000, No.4, pp. 72 - 74. 